\title{
When God is your only friend: Religious beliefs compensate for purpose in life in the socially disconnected
}

\section{Todd Chan ｜ Nicholas M. Michalak ｜ Oscar Ybarra}

University of Michigan

\section{Correspondence}

Todd Chan, Department of Psychology, University of Michigan, 530 Church Street, Ann Arbor, MI 48109-1043.

Email: toddchan@umich.edu

Funding information

Social Sciences and Humanities Research Council of Canada

\begin{abstract}
Objective: Social relationships supply purpose to life. How can socially disconnected people, who show lower levels of purpose, compensate for purpose in life? We propose that religious beliefs can compensate for the purpose in life that social relationships would otherwise provide, through providing (a) greater purpose to turn to and (b) divine figures that can substitute for social relationships.

Method: In three studies, we analyze three nationally representative and longitudinal data sets $(N=19,775)$ using moderated regression and cross-lagged panel analyses. Results: Consistent with our hypotheses, religious beliefs were of minimal influence on purpose in life for socially connected individuals, who already held higher levels of purpose than socially disconnected individuals. However, for socially disconnected individuals, being highly religious predicted higher levels of purpose in life.

Conclusions: Results suggest that although people primarily derive purpose from social relationships, socially disconnected individuals may leverage their religious beliefs for purpose and social comfort until they can reconnect.
\end{abstract}

\section{K E Y W O R D S}

interpersonal relationships, loneliness, purpose, religion, social support

\section{1 | INTRODUCTION}

Purpose drives people forward. To have purpose means people feel that their life consists of plans, goals, and direction that make life worth living (Reker, Peacock, \& Wong, 1987). But what drives purpose? Social relationships may be central in supplying purpose to people's lives (Ebersole, 1998). People's goals and plans are intertwined with other people: Whether planning one's life with one's partner, striving to support one's family, making plans with friends, or setting self-improvement goals to impress others, people drive purpose.

Importantly, the mind is not designed to deal with aimlessness in life: People naturally search for purpose, and having this sense of purpose is critical to psychological well-being (Pinquart, 2002; Reker et al., 1987; Ryff \& Singer, 1998). People who lack purpose in life report lower life satisfaction and optimism and higher levels of depression and anxiety; they are at greater risk for a host of psychological and physical health problems that, in short, put them at an overall higher mortality risk (Hill \& Turiano, 2014; Krause, 2009; McKnight \& Kashdan, 2009; Zika \& Chamberlain, 1992). So, what can people who are socially disconnected do to derive purpose in life? People who feel that they lack social connection from humans often turn to substituting nonhuman entities to help them feel socially connected (Epley, Waytz, Akalis, \& Cacioppo, 2008). Religious beliefs and the presence of God often act as sources of this social substitution (Aydin, Fischer, \& Frey, 2010). Given that religious beliefs are also associated with an increased sense of purpose in life (Chamberlain \& Zika, 1992), can religious beliefs act as a substitutive source of purpose in life for those who are socially disconnected? Although much research has been done showing that social disconnection is associated with loss of purpose, and people who are socially disconnected often turn to religious beliefs, no research has examined whether people 
who are socially disconnected and who turn to their religious beliefs may benefit by showing higher levels of purpose in life. Thus, we examine this question in the present research.

We propose that feeling socially disconnected is associated with a loss of purpose in life. However, we utilize theories of compensatory control and religious substitution to show how people who strongly hold religious beliefs may be buffered from this loss of purpose associated with social disconnection. Below, we further define purpose in life and then review the pathways through which (a) social connections can supply purpose and (b) religious beliefs can supply purpose. Then we link these two theoretical frameworks together to propose our model that religious beliefs can compensate as a source of purpose in life when people lack the purpose derived from social connection.

\section{1 $\mid$ Purpose in life}

Purpose is often conceptualized as being one facet of having broader meaning in life, but having purpose in life is distinct by being (a) future oriented and (b) broadly motivational (Martela \& Steger, 2016). Specifically, having meaning means one has coherence and understanding about one's life and that life events make sense; having purpose means one has future directions and goals that one believes are significant enough to strive and live for (Martela \& Steger, 2016). For example, individuals may not have meaning (i.e., understanding) about the circumstances of their life after a recent romantic breakup, but they may have broader purpose (i.e., striving) about their aims to be in a romantic relationship. Thus, whereas meaning serves to describe a present life state, purpose serves to motivate individuals into the future. Of course, one's future goals are often intertwined with one's understanding of one's present actions and events, and having both purpose and meaning contributes to a host of positive health outcomes (Krause, 2007a; Zika \& Chamberlain, 1992). Of note, although we specifically discuss purpose and use measures relating to this sense of future-oriented direction in this research, past research has generally used the term purpose interchangeably with broader constructs like meaning. Given the considerable overlap between the two constructs, we also refer to past research that has examined meaning more broadly.

\subsection{Social connections and purpose in life}

Feeling socially connected, already critical to feeling positively, thinking sharply, and being healthy, may also supply purpose to life. Specifically, having positive social relationships and strong levels of social support predicts enhanced purpose in life (George \& Park, 2013; Pinquart, 2002) and can be particularly helpful in restoring a loss of purpose in life caused by external life stressors (Krause, 2004). In fact, social relationships may be the most central factor underlying a sense of purpose in life (Ebersole, 1998).

Social relationships may supply purpose to life through three pathways. First, social relationships involve the exchange of instrumental and emotional support (Holt-Lunstad, Smith, \& Layton et al., 2010).

For example, when a friend is in need, individuals commonly provide direct assistance (i.e., instrumental support) or reassurance (i.e., emotional support). This provision of support and the knowledge that important others are dependent upon them can provide a sense of use and purpose to individuals' lives (Wong, 1998). Second, knowing that one is part of a network of relationships or belongs to a larger group can confer a sense of increased purpose through allowing people to identify with collective values and pursue common goals (Haslam, Jetten, Postmes, \& Haslam, 2009; Lambert et al., 2013). Third, interacting frequently with friends can increase the opportunities in which individuals can engage in other activities that provide purpose (Pinquart, 2002). In sum, social relationships provide opportunities for people to feel that they are needed, and this can confer a sense of purpose (Kawachi \& Berkman, 2001; Pinquart, 2002).

\section{3 | Social disconnection and loss of purpose}

Accordingly, when individuals are or feel socially disconnected-whether for extended periods or brieflythey are being relatively deprived of the social processes that supply purpose to life (Stillman et al., 2009). Social disconnection is a psychological state, where people appraise their social relationships to be lacking in quantity or quality.

First, social disconnection can mean the perception that one lacks one's desired quantity of social connection. People can have many supportive ties, yet still feel socially disconnected. Indeed, loneliness is defined as the feeling that occurs when there is a discrepancy between people's desired quantity of social connections and their appraised quantity of social connections (Cacioppo, Hawkley, \& Berntson, 2003). Research indicates that up to $30 \%$ of the population suffers from chronic loneliness (Heinrich \& Gullone, 2006). Critically, loneliness is associated with lower levels of purpose in life (Bondevik \& Skogstad, 2000).

Second, social disconnection can mean the perception that one lacks the desired quality of support provided from their social connections. For example, people can be satisfied with their number of friends, yet feel that these friends often cause more stress and strain rather than provide support. Critically, having supportive friends is arguably the most important factor in psychological well-being (Dunbar, 2018). Thus, in this present research, we consider social disconnection as reflecting both of these definitions: Loneliness and quality of friendship support. 
Thus, socially disconnected individuals either lack social relationships or are not benefiting from their existing ones (Cacioppo et al., 2003; Hawkley \& Cacioppo, 2010; Heinrich \& Gullone, 2006). Because socially disconnected individuals are deprived of sources of the purpose social relationships provide, over time these individuals show lower well-being (Krause, 2007b). In fact, through threatening people's psychological and physical well-being, social disconnection may increase individuals' overall mortality risk to one that is comparable to smoking (Holt-Lunstad et al., 2010).

How can people effectively deal with being socially disconnected? One way that is perennially suggested is for disconnected individuals to simply form new relationships or repair old ones (Baumeister \& Leary, 1995). However, given that the very nature of social disconnection means that one has negative social expectations, and often involves feeling as if one has lost existing relationships or is being rejected from new ones, making oneself further vulnerable by trying to connect with other people may not always be immediately feasible or appealing (Hawkley \& Cacioppo, 2010; Ren, Wesselmann, \& Williams, 2016). Accordingly, people have been found to deal with social disconnection not necessarily by connecting with other people, but by turning to beliefs and nonhuman figures (Epley, Waytz, \& Cacioppo, 2007; Kay, Whitson, Gaucher, \& Galinsky, 2009).

\section{4 | Religious beliefs as substitutive social connection}

When people's needs for social connection are threatened and other people are not available, they often turn to substituting nonhuman entities for social connection. For example, individuals who are chronically lonely are more likely to ascribe human-like traits, emotions, and agency to nonhuman things, such as pets, robots, and imaginary beings (Epley, Akalis, Waytz, \& Cacioppo, 2008; Epley, Waytz, et al., 2008; Niemyjska \& Drat-Ruszczak, 2013). Notably, people can also use their religious beliefs and God as a substitutive connection.

Much research supports this proposal that when people do not feel connected to others, they can substitute God for a social relationship. Of note, this relationship often only holds for religious people, who have these additional relationships with divine others to substitute. For example, individuals who have their belongingness threatened with discrimination, loneliness, or exclusion have all been found to increase their religious beliefs and their intentions to participate in religious activities, in an attempt to seek comfort from God (Aydin et al., 2010). Likewise, people who have recently experienced romantic rejection threats report feeling closer to God (Kirkpatrick, Shillito, \& Kellas, 1999; Laurin, Schumann, \& Holmes, 2014). In fact, people who show insecure attachment patterns are especially likely to see God as a replacement attachment figure (Granqvist, Mikulincer, $\&$ Shaver, 2009). More striking, individuals who are single (relative to people who are coupled) are more likely to be religious and report a strong personal relationship with God (Granqvist \& Hagekull, 2000). In sum, it appears that when people's needs for belonging and inclusion are not met, they may see God as a substitutive connection, whereas people with their belonging needs satisfied are less likely to show this religious substitution (Gebauer \& Maio, 2012).

\section{5 | Can religious beliefs supply purpose when people are socially disconnected?}

Our current focus, however, is on the downstream consequences of this religious substitution, namely, purpose in life. Research that looks at how people respond to social threats by increasing one's religious beliefs or relationship with God has often treated the belief in God as the final outcome and not examined how the strength of these beliefs impacts other psychological and behavioral outcomes. The research that does exist has suggested that this substitution can be beneficial. For example, individuals who are rejected and report turning to God show less aggressive tendencies (Aydin et al., 2010). Additionally, individuals who emphasize their religious beliefs after losing a spouse show lessened grief (Brown, Nesse, House, \& Utz, 2004). More generally, people who lack social support but report a strong relationship with God report lower levels of loneliness (Kirkpatrick et al., 1999). However, no research has shown the downstream effects of this substitution on purpose in life. Given that several findings indicate that religious beliefs supply a greater sense of purpose in life (Chamberlain \& Zika, 1992; Frazier, 2005; Park, 2005), there is good reason to expect that if religious beliefs are used for substitutive social connection, then they would buffer the loss of purpose that occurs from feelings of social disconnection.

Why might leveraging religious beliefs in the face of social disconnection bolster purpose in life? We offer two reasons that, when combined, may put religious beliefs in a unique position to compensate for purpose in life. First, religious beliefs provide a purposeful, broader worldview for people to turn to in lieu of social relationships. Second, religious beliefs provide substitutive relationships (i.e., with God) that may serve some of the same functions as human relationships.

First, religious beliefs are often composed of worldviews that help people explain or cope with uncertain and adverse events (e.g., death or tragedy), by proposing that these events "fit" within a larger plan or purpose-one created by a higher power (Berger, 1967). Thus, religious beliefs provide people with ways to interpret their present misfortune as part of future fulfillment (Baumeister, 1991). What is more notable, however, is that these stabilizing and explanatory features of religion are most likely to appeal to people who lack other 
ways of deriving broader meaning (Baumeister, 1991). It follows, then, that when purpose is otherwise threatened, religious beliefs may compensate for purpose by allowing people to assert that a higher power has a greater plan at work for them-a purpose greater than what may be presently afforded by their social connections (Krause, 2003). As such, people derive purpose from the broader tenets of religion that propose the future is nevertheless significant and will "work out."

Some research supports this proposal. The meaning-making model posits that a broad sense of meaning includes having global goals, or desired outcomes that people are motivated to reach (Park, 2005). Experiencing traumatic events (e.g., the death of a loved one) can threaten these global goals and the purpose they afford. In turn, people who have their purpose threatened are more likely to make attributions that a greater purpose from God, however nonunderstandable, is at play, and consequently, show better coping outcomes (Park, 2005; Park \& Cohen, 1993).

Aside from purpose, related research shows that when people's personal sense of meaning and control is threatened, they compensate by seeking out broader worldviews. For example, compensatory control theory finds that when people experience a personal loss of control, they increase their belief in religion and the presence of a controlling God, worldviews that impart order and control (Kay, Gaucher, McGregor, \& Nash, 2009; Kay, Gaucher, Napier, Callan, \& Laurin, 2008). Similarly, research in terror management theory has shown that people who are anxious with thoughts about death—which lead to loss of control and meaning - assert greater belief in prevailing cultural worldviews (Burke, Martens, \& Faucher, 2010). Taken together, we have reason to believe that those who lack purpose may benefit from the goals and plans imparted by the broader worldviews that religion affords.

Second, religious beliefs may also counter a loss in purpose by substituting the functions of human social relationships (Krause, 2003; Pollner, 1989). Religious beliefs are unique in that they provide "divine others" whom individuals can use as supplementary or substitutive relationships to real people (Pollner, 1989). Like relationships with other people, divine others may be able to provide support in negative situations, through individuals' believing that an omnipresent higher power who values them unconditionally can provide them with emotional strength or help them resolve the situation (Pollner, 1989). Conversing with, consulting, and seeking reassurance from a higher power are common activities for religious individuals, and those who are highly religious may feel particularly emotionally close and valued by a higher being, akin to feeling close and valued by a loved one (Pollner, 1989; Zika \& Chamberlain, 1992). Similarly, people who are highly religious are more likely to base their self-worth on God's love (Crocker, Luhtanen, Cooper, \&
Bouvrette, 2003). In sum, people are more likely to derive purpose because they feel that God is their partner, one who values and needs them.

In turn, when individuals feel socially disconnected, those who are highly religious should be able to more heavily emphasize their relationships with divine others and de-emphasize their relationships with other people (Laurin et al., 2014), shifting where they derive purpose in life. Similar research on meaning more broadly has shown that when people feel socially connected, their judgments of meaning in life are primarily derived from the highly salient information about their social belongingness (Hicks, Schlegel, \& King, 2010). However, when people lack a sense of social belongingness, they will turn to substitutive cues to inform and bolster their sense of meaning. For example, people who are lonely instead rely more on their level of positive affect (rather than their lack of social connections) to inform their sense of meaning (Hicks \& King, 2009). With religion, related work has also found that highly religious people rely less on their positive affect, deriving their meaning in life more so from their religious beliefs (Hicks \& King, 2008).

Combining and extending these lines of reasoning, we would analogously predict that individuals who are socially disconnected but highly religious may leverage their religious beliefs as the substitutive source for purpose. Thus, having a belief system that can sufficiently represent the functions served by social relationships may act as a protective factor for individuals who are not deriving purpose provided by positive social ties. In fact, because religious beliefs can confer both broader worldviews and divine relationships in one system at the same time, compared to other belief systems, they may be uniquely positioned and particularly appealing to leverage by those who lack purpose in life.

\section{6 | Overview of the present research}

In sum, past research shows that (a) social disconnection deprives people of purpose in life, and (b) religious beliefs can serve as substitutes for social connection. However, no research has looked at the intersection of these two notions: how religious substitution can affect people's perceptions of purpose in life when they are deprived of social connection. We aim to address this gap in the present work. We propose a model in which religious beliefs moderate the negative relationship between social disconnection and purpose in life. Individuals with high levels of social connection should report overall higher levels of purpose in life, and religiosity should have minimal additional influence on their reported purpose in life, as there is no need to invoke a compensatory worldview or the substitution of a divine being. Conversely, individuals with low levels of social connection should report overall lower levels of purpose in life. However, if religious beliefs can compensate for this purpose within this 
group, individuals with high religiosity should have higher purpose in life than individuals with low religiosity. Across three studies, we find support for this hypothesis by examining three large, nationally representative data sets that contain our constructs of interest: In Study 1, we examined how religious beliefs compensate for purpose in life and operationalize social disconnection with feelings of loneliness; in Study 2, we operationalize social disconnection with the perceived quality of friendship support. In Study 3, we provide further directional evidence with two time points indicating that highly religious individuals who lack quality social relationships are relatively buffered from losses of purpose in life over time.

\section{\begin{tabular}{l|l}
2 & STUDY 1
\end{tabular}}

\section{1 | Method}

\subsection{1 | Participants}

We examined data from the Health and Retirement Study (HRS; 2010 wave). In this wave of the study, 11,213 Englishspeaking American adults (4,713 male; 6,500 female) between the ages of 28 and $109(M=65.76, S D=11.91)$ were randomly selected from a larger longitudinal sample to complete extensive self-administered questionnaires (completion rate: $74 \%$ ), including our measures of interest. Of note, we selected this wave as it was the most recent wave in which a substantially new cohort completed these psychosocial measures for the first time. Respondents were 53.0\% White, 31.8\% Black or African-American, and 15.2\% other (including Asian, Pacific Islander, and American Indian). Respondents had a median education level of some college (on a 17-point scale assessing years of schooling from $0=$ no schooling to $17=$ post college $)$. Most respondents were presently unemployed (59.7\%), married (59.8\%), and religious (85.6\%). All measures described below were administered and analyzed from the HRS data collection.

\subsection{2 | Measures}

\section{Loneliness}

The HRS contains an 11-item scale $(\alpha=0.89)$, adapted from the UCLA Loneliness Scale (Russell, 1996), that assesses the extent to which individuals feel lonely (e.g., "How much of the time do you feel that there are people you can turn to?'). Respondents indicate how often they have experienced feelings of loneliness on a 3 -point scale $(1=$ often to $3=$ hardly ever or never). Certain items are negatively worded and reverse coded, such that higher mean composite scores reflect higher levels of loneliness. Although feelings of loneliness are not an objective measure of belonging or social connection, our present focus is on the subjective perception individuals have of their social ties. Given that loneliness reflects the discrepancy between individuals' desired and actual quantity of social ties (Cacioppo et al., 2003), we used this measure to operationalize social connection, where higher levels of loneliness reflect lower levels of social connection $(M=1.53, S D=0.44)$.

\section{Religiosity}

This four-item scale ( $\alpha=0.93)$, adapted from the Brief Multidimensional Measure of Religiousness/Spirituality (Fetzer Institute, 2003), assesses individuals' commitment to their religious beliefs (e.g., "I try hard to carry my religious beliefs over into all my other dealings in life") on a 6-point scale $(1=$ strongly disagree to $6=$ strongly agree $)$. Higher mean composite scores reflect higher religiosity $(M=4.94$, $S D=1.44)$.

\section{Purpose}

The seven-item $(\alpha=0.78)$ Purpose in Life scale (Ryff \& Keyes, 1995) assesses the extent to which individuals perceive a sense of coherent purpose in their lives (e.g., "I have a sense of direction and purpose in life") on a 6-point scale $(1=$ strongly agree to $6=$ strongly disagree $)$. Certain items are negatively worded and reverse coded, such that higher mean composite scores reflect higher levels of purpose in life $(M=4.64, S D=0.96)$. This measure was our primary dependent variable.

\section{Covariates}

We controlled for participants' demographic variables as described above (i.e., gender, age, highest level of education, primary racial background, whether currently married, and whether currently employed), given their established associations with religion and purpose in life (Steger, Oishi, \& Kashdan, 2009). Additionally, we controlled for respondents' primary religious preference (i.e., Protestant, Catholic, Jewish, other, or no preference) and frequency of religious attendance $(1=$ more than once $a$ week to $5=$ not at all $)$, as we theorized that it was specifically the strength of individuals' religious beliefs (i.e., religiosity), rather than any particular religion or the social interaction associated with religious attendance, that would have an influence on compensating for purpose in life. The results reported reflect a model with covariates added; removing covariates does not significantly alter the pattern of results. Zero-order correlations among covariates and the variables of interest are detailed in Table 1 .

\subsection{Results}

Our primary question was, could religiosity compensate for the purpose in life that those who are socially disconnected lack? We conducted a moderated regression analysis to test 
TA B L E 1 Study 1: Summary of bivariate correlations among continuous variables of interest and associated covariates

\begin{tabular}{|lcccc} 
& $\mathbf{1}$ & $\mathbf{2}$ & $\mathbf{3}$ & $\mathbf{4}$ \\
\hline 1. Religiosity & & & & $\mathbf{5}$ \\
\hline 2. Loneliness & $-0.074^{* *}$ & & & \\
\hline 3. Purpose in life & $0.094^{* *}$ & $-0.450^{* *}$ & $-0.139^{* *}$ & $-0.049^{* *}$ \\
\hline 4. Age & $0.086^{* *}$ & $-0.043^{* *}$ & $0.133^{* *}$ & $-0.051^{* *}$ \\
\hline 5. Highest level of education & $-0.156^{* *}$ & $-0.118^{* *}$ & $-0.129^{* *}$ & 0.025 \\
\hline 6. Religious attendance & $-0.379^{* *}$ & $0.137^{* *}$ & & \\
\hline
\end{tabular}
$* p<0.05 .{ }^{* *} p<0.01 .{ }^{* * *} p<0.001$.

T A B L E 2 Study 1: Moderated regression model of loneliness and religiosity on purpose in life with covariates

\begin{tabular}{|c|c|c|c|c|c|c|c|}
\hline Coefficient & $b$ & $b^{*}$ & $S E$ & $t$ & $p$ & 95\% CI upper & $\begin{array}{c}95 \% \mathrm{CI} \\
\text { lower }\end{array}$ \\
\hline Intercept & 4.77 & 4.69 & 0.12 & 41.21 & $<0.001$ & 4.54 & 5.00 \\
\hline Female & 0.00 & 0.00 & 0.04 & 0.04 & 0.969 & -0.08 & 0.08 \\
\hline White & -0.30 & -0.11 & 0.06 & -4.99 & $<0.001$ & -0.41 & -0.18 \\
\hline Married & 0.15 & 0.04 & 0.21 & 0.74 & 0.459 & -0.25 & 0.56 \\
\hline Annulled & 0.92 & 0.02 & 0.97 & 0.94 & 0.346 & -0.99 & 2.82 \\
\hline Separated & 0.15 & 0.01 & 0.27 & 0.57 & 0.572 & -0.38 & 0.68 \\
\hline Divorced & -0.11 & -0.02 & 0.22 & -0.52 & 0.604 & -0.53 & 0.31 \\
\hline Education & 0.02 & 0.08 & 0.01 & 3.47 & 0.001 & 0.01 & 0.04 \\
\hline Protestant & -0.17 & -0.05 & 0.10 & -1.63 & 0.104 & -0.36 & 0.03 \\
\hline Catholic & 0.04 & 0.01 & 0.11 & 0.40 & 0.691 & -0.17 & 0.25 \\
\hline Jewish & -0.18 & -0.02 & 0.30 & -0.59 & 0.555 & -0.77 & 0.42 \\
\hline No religious preference & 0.20 & 0.04 & 0.12 & 1.66 & 0.097 & -0.04 & 0.43 \\
\hline Religious attendance & 0.01 & 0.02 & 0.02 & 0.76 & 0.447 & -0.02 & 0.04 \\
\hline Loneliness & -0.86 & -0.37 & 0.04 & -19.07 & $<0.001$ & -0.94 & -0.77 \\
\hline Religiosity & 0.07 & 0.10 & 0.02 & 4.41 & $<0.001$ & 0.04 & 0.10 \\
\hline Loneliness $\times$ Religiosity & 0.07 & 0.04 & 0.03 & 2.58 & 0.010 & 0.02 & 0.13 \\
\hline
\end{tabular}

Note. $F(20,1635)=34.67, p<0.001$, adjusted $R^{2}=0.289$. Religiosity and loneliness were centered around their grand means. Categorical variables were coded so that each estimate reflects the group's mean difference from the grand mean.

whether religiosity moderated the relationship between loneliness and purpose in life: Our covariates, mean-centered primary predictors-loneliness and religiosity - and the interaction of these two predictors were regressed on purpose in life. The final model was significant. As expected, higher levels of loneliness predicted lower levels of purpose in life, whereas higher levels of religiosity predicted higher levels of purpose in life. Notably, however, there was a significant interaction between loneliness and religiosity on purpose in life, indicating that the predictive relationship between social connectedness and purpose in life significantly differed depending on individuals' level of religiosity. Regression coefficients are detailed in Table 2.

We examined the simple slopes for individuals at high (i.e., $+1 S D ; b=-0.75, S E b=0.06, t=-11.69, p<0.001$ ) and low (i.e., $-1 S D ; b=-0.96, S E b=0.05, t=-17.53, p<$ $0.001)$ levels of religiosity, which significantly differed from each other $(p<0.001)$. As depicted in Figure 1, for individuals low in loneliness (i.e., high in social connectedness), religiosity has minimal influence on reports of purpose in life. Conversely, when individuals are high in loneliness (i.e., low in social connectedness), highly religious individuals report 
F I G URE 1 Religiosity moderates the relationship between loneliness and purpose in life (Study 1)

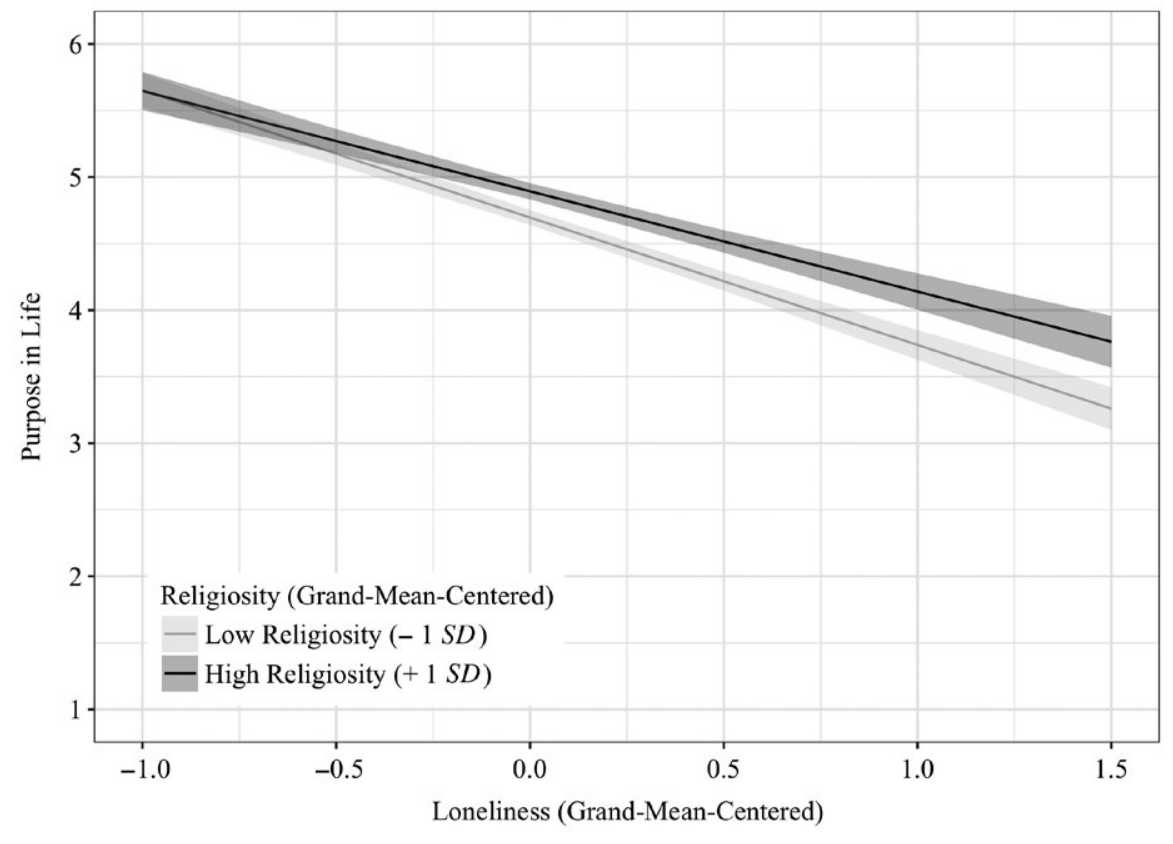

higher levels of purpose in life than individuals not highly religious. In support of our hypotheses, these results suggest that when individuals are highly socially connected, their purpose in life may be primarily derived from their social relationships, with religious beliefs providing little additional influence. However, when social relationships are lacking, religious beliefs may be able to help compensate for the loss of purpose in life: Within this group, individuals who are high in religiosity reported higher levels of purpose in life than individuals who are low in religiosity.

Indeed, these results suggest that individuals who lack quality social ties and who are highly religious may benefit from the broader worldview that religious beliefs afford. For example, on the present measure of religiosity, respondents were asked to what extent they believed that events unfolded by divine plan. It is possible that endorsing these beliefs that there is a greater purpose beyond one's life acts as a compensatory worldview, which individuals lacking purpose from social relationships can turn toward. In sum, thinking that there is a greater purpose that transcends oneself may be adaptive for those whose personal purpose - as derived from supportive relationships-is threatened.

\section{$3 \mid$ STUDY 2}

In Study 2, we sought to replicate the findings of Study 1, operationalizing religiosity and social disconnection differently. We operationalized religiosity with a measure of religious coping, or how likely people are to turn to their religious beliefs and God to deal with problems. That is, individuals who lack quality social connection, but who use their religious beliefs and God as sources of support, akin to how they would perceive relationally close others, may compensate for the purpose in life that they would otherwise receive from social relationships. We also operationalized social disconnection using a measure of perceived friendship quality.

\section{1 | Method}

\subsection{1 | Participants}

We examined data from the National Survey of Midlife Development in the United States (MIDUS 2; 2004-2006). ${ }^{1}$

Respondents were 5,268 nationally representative Englishspeaking American adults (2,316 male; 2,647 female) between the ages of 28 and $84(M=55.30, S D=12.42)$ who completed extensive self-administered questionnaires (completion rate: $81 \%$ ). Respondents were $84.9 \%$ White, $4.3 \%$ Black or African-American, 1.5\% Native American, 0.5\% Asian, $0.1 \%$ Pacific Islander, and $2.4 \%$ other. Respondents had a median education level of some college (on a 12-point scale ranging from $1=$ no schooling to $12=$ doctoral degree). Most respondents were presently employed (49.2\%), married $(66.5 \%)$, and religious $(87.2 \%)$. All measures described below were administered and analyzed from the MIDUS 2 data collection. ${ }^{2}$

\subsection{2 | Measures}

\section{Friendship quality}

To assess social connectedness, we used the Friendship Affectual Solidarity (Walen \& Lachman, 2000). This eightitem scale $(\alpha=0.77)$ created for the MIDUS 2 consists of four items that assess the extent to which individuals perceive their friends to be sources of support (e.g., "How much 
can you rely on them for help if you need to talk about your worries?") and four items that assess the extent to which individuals perceive their friends to be sources of strain (e.g., "How often do they let you down when you are counting on them?") on a 4-point scale $(1=a$ lot to $4=$ not at all $)$. The friend-support items are reverse coded, and the support and strain items are averaged, such that higher total composite scores reflect higher levels of friend support. We used this measure to operationalize social connection, where higher scores reflect a higher perception that one has supportive friendship ties $(M=3.22, S D=0.44)$.

\section{Religiosity}

In this study, we used the Religious/Spiritual Coping B Scale (Ryff, Singer, \& Palmersheim, 2004). This six-item scale ( $\alpha$ $=0.74)$, also adapted from the Multidimensional Measure of Religiousness/Spirituality (Fetzer Institute, 2003), assesses the extent to which individuals utilize religion and God as a resource for coping with problems (e.g., "I work together with God as partners") on a 4-point scale $(1=$ a great deal to $4=$ none). Of note, the items on this measure specifically refer to how individuals perceive their relationship with God as an agent (vs. their religious beliefs in general). Certain items are negatively worded and reverse coded, such that higher summed scores reflect higher religious coping. We used this scale as our measure of religiosity $(M=18.54$, $S D=3.85)$.

\section{Purpose in life}

As in Study 1, we used the seven-item $(\alpha=0.70)$ Purpose in Life scale (Ryff \& Keyes, 1995) to assess the extent to which individuals perceive a sense of coherent purpose in their lives (e.g., "I have a sense of direction and purpose in life") on a 7 -point scale $(1=$ strongly agree to $7=$ strongly disagree $) .{ }^{3}$ Certain items are negatively worded and reverse coded, such that higher summed scores reflect higher levels of purpose in life $(M=38.40, S D=6.97)$.

Covariates As in Study 1, we controlled for participants' demographic variables (i.e., gender, age, highest level of education, primary racial background, marital status, employment status, primary religious preference [Protestant, Catholic, Jewish, other, or nontheist]) and frequency of religious attendance $(1=$ several times $a$ day to $6=$ never $)$. All results reported reflect a model with covariates added; removing covariates does not significantly alter the pattern of results. Zero-order correlations among covariates and the variables of interest are detailed in Table 3.

\section{2 | Results}

Our primary analysis was whether a tendency to engage in religious coping could buffer the loss of purpose in life that individuals with unsupportive relationships experience. We conducted a moderated regression analysis to test whether religiosity moderated the relationship between friendship quality and purpose in life. As in Study 1, we regressed our covariates, friendship quality, religiosity, and the interaction term of these two predictors on purpose in life. The final model was significant. Specifically, higher levels of friendship quality and religiosity both predicted higher levels of purpose in life. In addition, there was a significant interaction of friendship quality and religiosity on purpose in life, indicating that the predictive relationship between friendship quality and purpose in life significantly differed depending on individuals' level of religiosity. Regression covariates are detailed in Table 4.

We examined the simple slopes for individuals at high (i.e., $+1 S D ; b=4.13, S E b=0.34, t=12.03, p<0.001)$ and low (i.e., $-1 S D ; b=5.24, S E b=0.32, t=16.39, p<0.001$ ) levels of religiosity, which significantly differed from each other $(p<$ 0.001 ). Consistent with the pattern of results in Study 1, for individuals with low friendship quality (i.e., social connectedness), religiosity appears to provide a benefit: Individuals who have low friendship quality and are high in religiosity report higher levels of purpose in life than individuals who are low in religiosity. Although religiosity appears to also provide a benefit for individuals who report high friendship quality, the discrepancy in reports of purpose in life between highly and lowly religious individuals decreases for these socially connected individuals, suggesting that religiosity has less of an influence when individuals are in quality social relationships (Figure 2).

T A B L E 3 Study 2: Summary of bivariate correlations among continuous variables of interest and associated covariates

\begin{tabular}{|c|c|c|c|c|c|}
\hline & 1 & 2 & 3 & 4 & 5 \\
\hline 2. Friendship quality & $0.189^{* * *}$ & & & & \\
\hline 4. Age & $0.111^{* * *}$ & $0.110^{* * * *}$ & $-0.065^{* * *}$ & & \\
\hline 5. Highest level of education & -0.038 & $0.045^{* * * *}$ & $0.198^{* * * *}$ & $-0.144^{* * *}$ & \\
\hline
\end{tabular}


TA B L E 4 Study 2: Moderated regression model of friendship quality and religiosity on purpose in life with covariates

\begin{tabular}{|c|c|c|c|c|c|c|c|}
\hline Coefficient & $b$ & $b^{*}$ & $S E$ & $t$ & $p$ & 95\% CI lower & 95\% CI upper \\
\hline Age & -0.02 & -0.03 & 0.01 & -1.93 & 0.054 & -0.04 & 0.00 \\
\hline White & 1.81 & 0.05 & 1.21 & 1.49 & 0.136 & -0.57 & 4.18 \\
\hline Black & 3.20 & 0.06 & 1.49 & 2.15 & 0.032 & 0.28 & 6.12 \\
\hline Asian & -3.13 & -0.04 & 2.58 & -1.21 & 0.224 & -8.18 & 1.92 \\
\hline Native Hawaiian & -3.91 & -0.05 & 5.20 & -0.75 & 0.453 & -14.10 & 6.29 \\
\hline Education & 0.42 & 0.15 & 0.04 & 10.24 & $<0.001$ & 0.34 & 0.51 \\
\hline Married & 3.09 & 0.14 & 0.47 & 6.61 & $<0.001$ & 2.18 & 4.01 \\
\hline Working & 1.06 & 0.08 & 0.23 & 4.71 & $<0.001$ & 0.62 & 1.51 \\
\hline Catholic & -0.63 & -0.03 & 0.51 & -1.22 & 0.222 & -1.63 & 0.38 \\
\hline Protestant & -0.80 & -0.04 & 0.47 & -1.70 & 0.089 & -1.73 & 0.12 \\
\hline Jewish & 1.88 & 0.05 & 1.07 & 1.76 & 0.079 & -0.22 & 3.97 \\
\hline Nontheist & 0.15 & 0.00 & 1.01 & 0.14 & 0.885 & -1.84 & 2.14 \\
\hline Religious attendance & -0.01 & 0.00 & 0.09 & -0.17 & 0.868 & -0.19 & 0.16 \\
\hline Friendship quality & 4.68 & 0.29 & 0.24 & 19.63 & $<0.001$ & 4.22 & 5.15 \\
\hline Religiosity & 0.33 & 0.18 & 0.03 & 9.70 & $<0.001$ & 0.26 & 0.39 \\
\hline $\begin{array}{l}\text { Friendship } \\
\text { quality } \times \text { Religiosity }\end{array}$ & -0.14 & -0.03 & 0.06 & -2.41 & 0.016 & -0.26 & -0.03 \\
\hline
\end{tabular}

Note. $F(21,3,328)=46.88, p<0.001$, adjusted $R^{2}=0.200$. Religiosity and friendship quality were centered around their grand means. Categorical variables were coded so that each estimate reflects the group's mean difference from the grand mean.

The present results further bolster the notion that social relationships are a central, and perhaps sufficient, influence to providing purpose in life. When individuals have quality social relationships (i.e., high social connectedness), their purpose in life may be driven in large part by these social relationships. Religious beliefs provide little distinction in purpose in life for these socially connected individuals, perhaps because when belongingness needs are met, it is not necessary to leverage religious beliefs as a compensatory source of purpose. Individuals who lack these positive social relationships, as indexed by friendships characterized by low support and high strain, showed overall much lower levels of purpose in life than individuals who had supportive social connections. But, within this socially disconnected group, individuals high in religiosity reported higher purpose in life than individuals low in religiosity. Religious beliefs (specifically the tendency to turn to religion as a coping resource) helped counter this threat to purpose in life, perhaps because religion uniquely acts as a broader source of purpose and as a substitutive source of the functions social relationships typically serve.

\section{\begin{tabular}{l|l}
4 & STUDY 3
\end{tabular}}

In Study 3, we provide further evidence suggesting not only that the moderated relationships found in Study 2 are crosssectional, but also that religiosity bolsters purpose in life for the socially disconnected over time. In Study 3, our goals were to (a) replicate the results found in Study 2 using another wave of nationally representative data, and (b) combined with the data from Study 2, demonstrate that religiosity buffers loss of purpose over time for individuals who are socially disconnected.

\section{1 | Method}

\subsection{1 | Participants}

We examined data from the National Survey of Midlife Development in the United States (MIDUS 3; 2013-2014). This wave of data is analogous to the data presented in 
FIGURE 2 Religiosity moderates the relationship between friendship quality and purpose in life (Study 2)

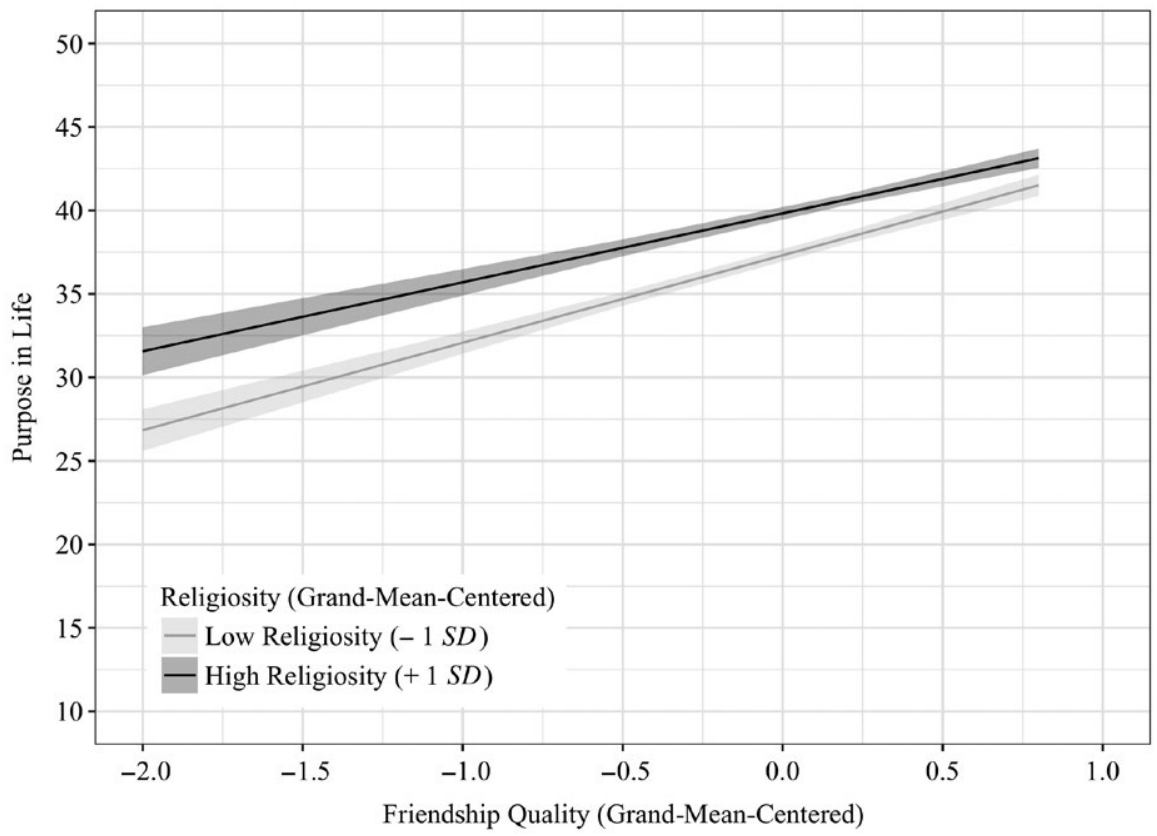

Study 2, and it includes both new participants and a subset of longitudinal participants from Study 2. Respondents were 3,294 nationally representative English-speaking American adults (1,484 male; 1,810 female) between the ages of 39 and $93(M=63.64, S D=11.35)$ who completed extensive self-administered questionnaires (completion rate: $81 \%$ ). Respondents were $89.5 \%$ White, 3.7\% Black or AfricanAmerican, 0.9\% Native American, 0.4\% Asian, and 5.5\% other. Respondents had a median education level of some college (on a 12-point scale ranging from $1=$ no schooling to $12=$ doctoral degree). Most respondents were presently employed (51.7\%), married (67.2\%), and religious (83.2\%).

\subsection{2 $\mid$ Measures}

The measures analyzed in Study 3 were the same as those used in Study 2. Friendship quality $(\alpha=0.78 ; M=3.29$, $S D=0.45)$, religiosity $(\alpha=0.72 ; M=18.50, S D=3.83)$, and purpose in life $(\alpha=0.72 ; M=38.10, S D=7.02)$ were the primary variables of interest. The covariates we considered were also the same as in Study 2. Zero-order correlations among covariates and the variables of interest are detailed in Table 5.

\section{2 $\quad$ Results}

First, we sought to replicate the pattern of results found in Study 2 with a new wave of data that included new respondents. To review, we examined whether religiosity, and specifically religious coping, could buffer the loss of purpose in life that individuals with unsupportive relationships experience. As in Study 2, we conducted a moderated regression, and the final model was significant. As expected, higher levels of friendship quality and religious coping both predicted higher levels of purpose in life, but there was also a significant interaction of friendship quality and religiosity on purpose in life. Regression coefficients are detailed in Table 6. As in Study 2 , we examined the simple slopes for individuals at high (i.e., $+1 S D ; b=3.42, S E b=0.42, t=8.21, p<0.001)$ and low (i.e., $-1 S D ; b=4.49, S E b=0.39, t=11.53, p<0.001$ ) levels of religiosity, which significantly differed from each other $(p<0.001)$. Replicating the pattern of results in Study 2, for

TA B L E 5 Study 3: Summary of bivariate correlations among continuous variables of interest and associated covariates

\begin{tabular}{lcccc} 
& $\mathbf{1}$ & $\mathbf{2}$ & $\mathbf{3}$ & $\mathbf{4}$ \\
\hline 1. Religiosity & & & & \\
\hline 2. Friendship quality & $0.189^{* * *}$ & & & \\
\hline 3. Purpose in life & $0.199^{* * *}$ & $0.299^{* * *}$ & & \\
\hline 4. Age & $0.070^{* * *}$ & $0.069^{* * *}$ & $-0.067^{* * *}$ & $-0.144^{* * *}$ \\
\hline 5. Highest level of education & $-0.076^{* * *}$ & 0.039 & $0.209^{* * *}$ & $-0.154^{* * *}$ \\
\hline 6. Religious attendance & $-0.576^{* * *}$ & $-0.118^{* * *}$ & $-0.138^{* * *}$ & -0.029 \\
\hline
\end{tabular}

${ }^{*} p<0.05 .{ }^{* *} p<0.01 .{ }^{* * *} p<0.001$. 
T A B L E 6 Study 3: Moderated regression model of friendship quality and religiosity on purpose in life with covariates

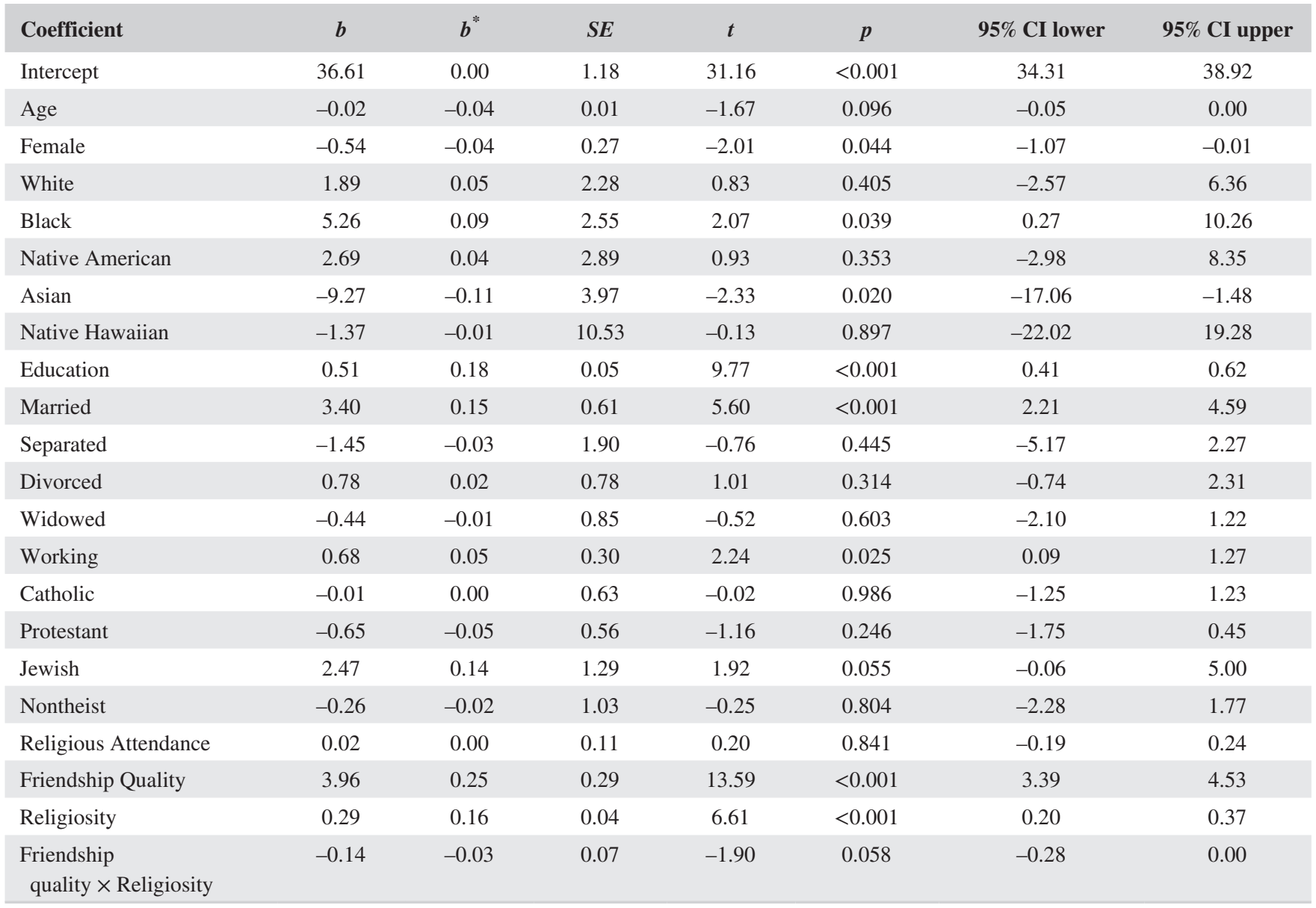

Note. $F(21,2,492)=26.88, p<0.001$, adjusted $R^{2}=0.178$. Religiosity and friendship quality were centered around their grand means. Categorical variables were coded so that each estimate reflects the group's mean difference from the grand mean.

individuals with low friendship quality, those higher in religiosity report greater levels of purpose in life than individuals lower in religiosity. Although religiosity appears to also provide a benefit for individuals who have high friendship quality, the discrepancy in reports of purpose in life between individuals higher and lower in religiosity is minimal for the better socially connected individuals. These results further bolster the finding that religiosity has a greater benefit for purpose in life for those who lack quality, supportive social relationships (Figure 3).

Second, however, we were interested in whether religiosity—specifically, religious coping-could predict increased purpose in life over time, particularly for individuals who were socially disconnected. We thus examined data from both MIDUS 2 (Time 1) and MIDUS 3 (Time 2) in a crosslagged panel design to test whether friendship quality at Time 1 predicted purpose in life at Time 2, and whether this relationship depended on religiosity. The primary predictors at each wave were grand-mean-centered and an interaction term computed. Then we fitted a structural equation model in which we (a) regressed purpose in life at Time 2 onto friendship quality, religiosity, and their interaction from Time 1; (b) regressed friendship quality, religiosity, and their interaction from Time 2 on purpose in life at Time 1 to control for the reverse path; and (c) regressed each Time 2 variable on its Time 1 equivalent (i.e., autoregressive paths). Paths of interest from this model are depicted in Figure 4; standardized regression estimates for each of these paths are detailed in Table 7. As in the previous studies, we conducted our crosslagged panel analysis with and without covariates at both time points. ${ }^{4}$ For ease of interpretability of the coefficients, we report the cross-lagged panel analysis without covariates. The patterns of interest are illustrated in Figure 4 and the coefficients for each path are detailed in Table 7 .

Having both lower friendship quality and lower religiosity at Time 1 predicted having lower purpose in life at Time 2. However, a significant interaction of religiosity and friendship quality at Time 1 also emerged (see boldfaced path in Figure 4). To illustrate the interaction, we examined individuals at high (i.e., $+1 S D$ ) and low (i.e., $-1 S D$ ) levels of friendship quality at Time 1. Specifically, for individuals who had low friendship quality (i.e., social connections), religiosity positively predicted purpose in life at Time 2 (estimate $=0.156, S E=0.04, z=3.86, p<0.001)$. However, 
F I GURE 3 Religiosity moderates the relationship between friendship quality and purpose in life (Study 3)

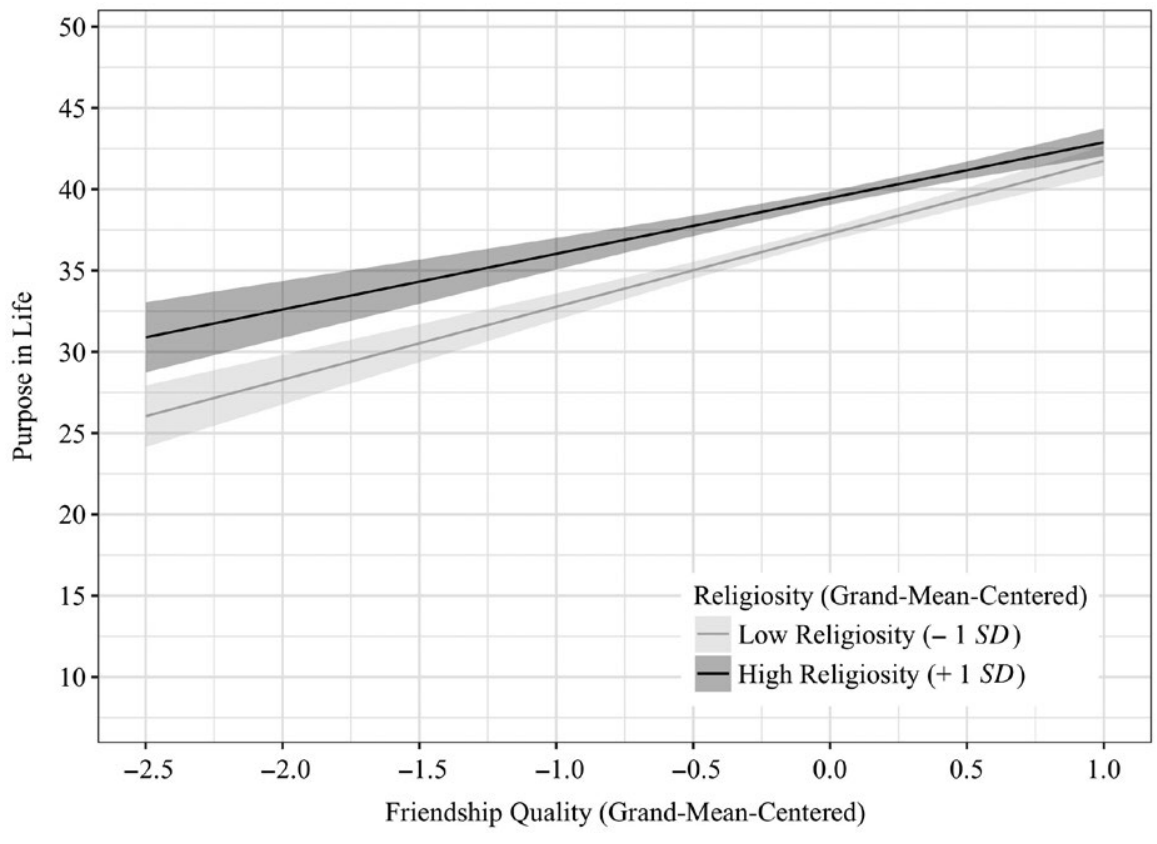

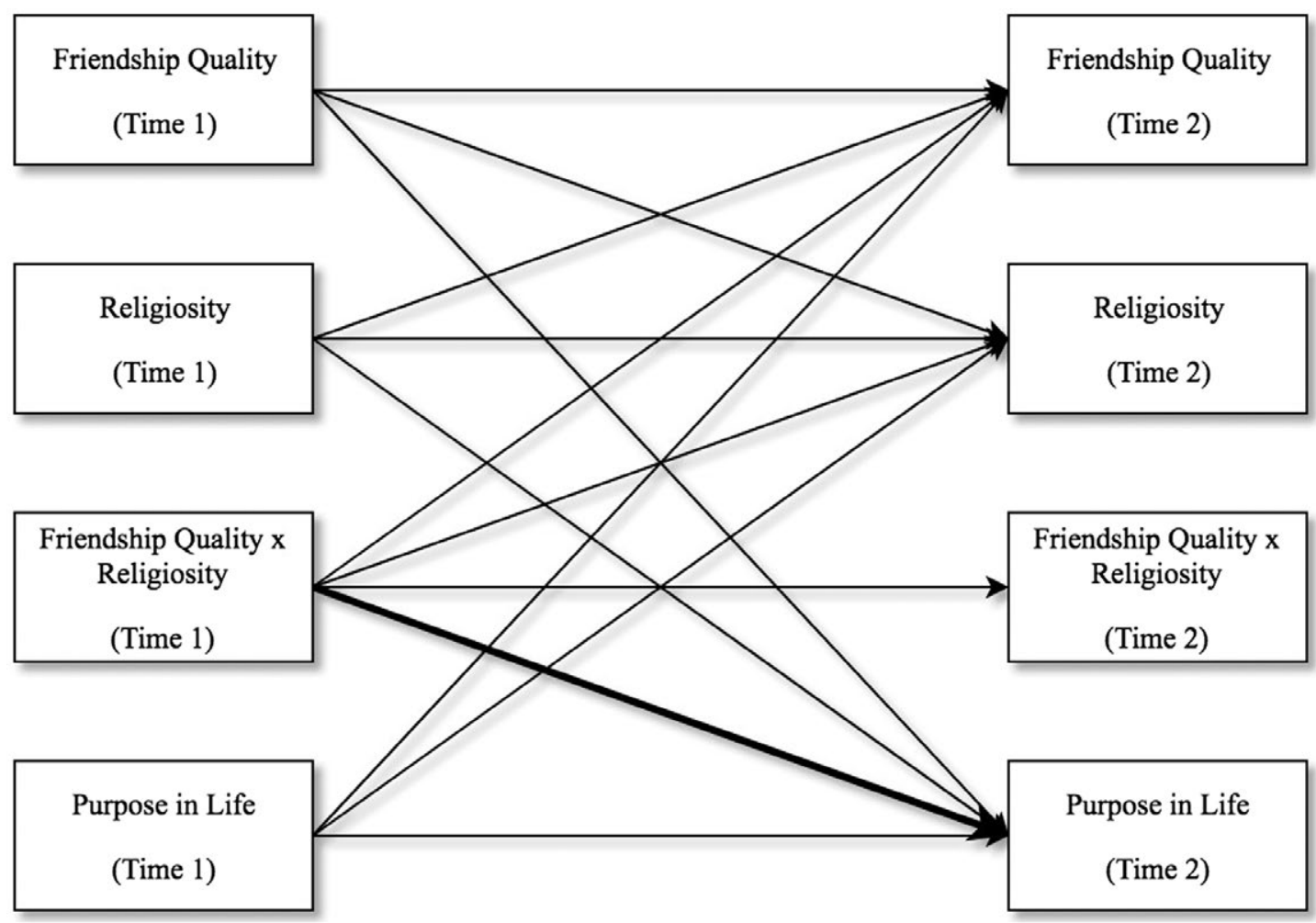

F I G U RE 4 Reciprocal time-lagged effects between friendship quality, religiosity, and their interaction term (Study 3). Note. The bolded line depicts the primary path of interest: the interaction at Time 1 predicting purpose in life at Time 2

for individuals who had high friendship quality, religiosity did not predict purpose in life at Time 2 (estimate $=0.04$, $S E=0.038, z=1.15, p=0.251$ ), suggesting that religiosity bolsters purpose in life over time only in the socially disconnected.
These longitudinal findings are consistent with our expected pattern and with our past studies. For socially connected people, religiosity has minimal additional influence on purpose in life over time, perhaps because of the central role of social relationships in supplying purpose. However, for socially disconnected people, religiosity may serve to 
TA B L E 7 Study 3: Standardized regression coefficients from structural equation model

\begin{tabular}{|c|c|c|c|c|c|c|c|c|}
\hline Outcome & Predictor & $b$ & $b^{*}$ & $S E$ & $z$ & $p$ & $\begin{array}{l}\text { 95\% CI } \\
\text { lower }\end{array}$ & 95\% CI upper \\
\hline Purpose in life $\mathrm{T} 2$ & Purpose in life T1 & 0.637 & 0.626 & 0.017 & 38.510 & $<0.001$ & 0.605 & 0.670 \\
\hline Purpose in life $\mathrm{T} 2$ & Religiosity T1 & 0.100 & 0.054 & 0.028 & 3.568 & $<0.001$ & 0.045 & 0.154 \\
\hline Purpose in life T2 & $\begin{array}{l}\text { Friendship } \\
\text { Quality } \times \text { Religiosity T1 }\end{array}$ & -0.127 & -0.030 & 0.063 & -2.015 & 0.044 & -0.250 & -0.003 \\
\hline Friendship quality T2 & Purpose in life T1 & 0.008 & 0.121 & 0.001 & 6.501 & $<0.001$ & 0.005 & 0.010 \\
\hline Friendship quality T2 & Friendship quality T1 & 0.470 & 0.455 & 0.019 & 24.918 & $<0.001$ & 0.433 & 0.507 \\
\hline Friendship quality $\mathrm{T} 2$ & Religiosity T1 & 0.009 & 0.075 & 0.002 & 4.371 & $<0.001$ & 0.005 & 0.013 \\
\hline Friendship quality T2 & $\begin{array}{l}\text { Friendship } \\
\text { Quality } \times \text { Religiosity T1 }\end{array}$ & -0.012 & -0.046 & 0.005 & -2.702 & 0.007 & -0.021 & -0.003 \\
\hline Religiosity T2 & $\begin{array}{l}\text { Friendship qual- } \\
\text { ity } \times \text { Religiosity T1 }\end{array}$ & 0.061 & 0.027 & 0.031 & 1.967 & 0.049 & 0.000 & 0.122 \\
\hline $\begin{array}{l}\text { Friendship } \\
\text { quality } \times \text { Religiosity } \\
\text { T2 }\end{array}$ & $\begin{array}{l}\text { Friendship } \\
\text { quality } \times \text { Religiosity } \mathrm{T} 1\end{array}$ & 0.393 & 0.377 & 0.019 & 20.402 & $<0.001$ & 0.355 & 0.431 \\
\hline
\end{tabular}

Note. $\chi^{2}(d f=3)=5.32$, RMSEA $=0.014[0.00,0.032]$, TLI $=0.996$, SRMR $=0.01$.

act as a compensatory resource. Only for people who lacked social connections, greater religiosity at Time 1 predicted increased purpose in life at Time 2, whereas we found no evidence that religiosity mattered for individuals who were high in social connectedness. This pattern of findings suggests that those who can leverage their religious beliefs can partly compensate for the purpose in life that would otherwise be obtained through having positive social relationships.

\section{5 | GENERAL DISCUSSION}

Our goal in the current work was to examine whether individuals who lacked quality social connections could restore a sense of purpose to their lives by leveraging the substitutive benefits for purpose that religion affords. Across three studies, the pattern of results supported this

proposal: Having a firmly held religious belief system may be one way socially disconnected individuals can cope with threatened purpose in life.

In Studies 1 and 2, we showed that for those who had high levels of social connection (i.e., low loneliness), religiosity minimally distinguished individuals' levels of purpose in life. However, for individuals who had low levels of social connection (i.e., high loneliness), religiosity predicted higher levels of purpose in life.

It appears that highly religious individuals who face social threats to purpose may effectively turn toward their beliefs.
These beliefs may provide a sense of increased purpose about the world. In turn, this sense that there is a greater purpose at play-beyond individuals' own lives-may supply individuals with a greater sense of personal purpose despite being socially disconnected (Klinger, 1998). In addition, religious beliefs may specifically benefit those who lack social connections because of their ability to substitute for social relationships (Pollner, 1989).

In Study 3, we provided further support by replicating the pattern found in Study 2, and by providing longitudinal evidence that religious coping bolsters purpose in life for those who lack supportive social relationships. Over time, people can vary in purpose in life and in the quality of their social ties (or lack thereof). However, our results that combined two longitudinal waves of data suggest that beyond these variations, those who lack supportive social ties are also more likely to lack purpose in life over time, but only when they lacked religion as a compensatory resource. Those who could leverage their religious beliefs did not show this decline in purpose in life over time. Combined, these results suggest that those who strongly hold religious views may be buffered from a loss of purpose due to a lack of social connection because they are able to sufficiently substitute some of the functions served by social relationships with religious worldviews and God.

Importantly, given work that shows that the quantity and quality of social relationships can act as separate predictors (House, Landis, \& Umberson, 1988), we examined the 
relationship between two different aspects of social connection and purpose in life. In Study 1, we operationalized social connection with loneliness, or the extent to which individuals felt that they had their desired quantity of positive social ties. In Studies 2 and 3, we focused on the quality of individuals' existing social ties, by operationalizing social connection as the extent to which individuals felt that their social ties overall provided them with high levels of support and low levels of strain. Together, we found that both perceived low quantity and low quality of social relationships act in similar ways with regard to predicting decreased purpose in life.

\section{6 | IMPLICATIONS}

Across all three studies, we consistently found relatively large effect sizes $\left(b^{*}\right.$ range $\left.=|0.27-0.39|\right)$ in the predictive relationships between social connectedness and purpose in life: Regardless of religiosity, socially disconnected individuals reported lower levels of purpose in life. The most noteworthy effect, however, is that religiosity consistently and robustly changed the strength of these relationships. Although the effect is relatively modest in size $\left(b^{*}\right.$ range $\left.=10.04-0.071\right)$, given the already large relationships between social connectedness and religiosity, we find it notable that religiosity nevertheless changes these relationships, both cross-sectionally and longitudinally (Gignac \& Szodorai, 2016; Prentice \& Miller, 1992). Thus, highly religious individuals may be able to use their religious beliefs to substitute the purpose usually derived from social relationships.

In turn, although the present work does not suggest that people who are highly religious can sufficiently restore purpose and recover from social disconnection by turning to their religious beliefs, these findings do suggest that religious beliefs facilitate psychological processes that have practical benefits for purpose. In particular, in the face of painful social disconnection, these omnipresent beliefs may especially benefit those who may not have other sources of purpose to turn to or other coping resources to seek out. Accordingly, the present findings add to a burgeoning body of work showing that, at least for those who are religious, religious beliefs can realistically act as a stabilizing force that provides predictability and purpose-especially when these things are lacking in one's life (Chamberlain \& Zika, 1992; McIntosh, 1995; Park, 2005).

Although our present findings focus on comparisons involving religious individuals, our theory proposes that it is the broader purpose and worldview that religion confers that provide these benefits for people's purpose. Thus, this suggests that analogous, nonreligious worldviews may confer the same benefits. For example, some research suggests that holding a scientific worldview (i.e., believing in science) confers comparable benefits for coherence and stability, and can help individuals cope with stress and anxiety (Farias, Newheiser, Kahane, \& De Toledo, 2013). Across cultures, people who hold views about science and technology as benefiting society have higher perceptions of personal control, which in turn bolster life satisfaction (Stavrova, Ehlebracht, $\&$ Fetchenhauer, 2016). Thus, even for nonreligious individuals, holding worldviews such as these may likewise benefit their purpose in life when social disconnection occurs. Of course, what remains unclear is whether individuals holding faith in science can likewise engage in social substitution to bolster purpose. Additionally, it is unclear whether individuals can "adopt" these beliefs if they do not already endorse these worldviews to benefit their purpose in life amidst threat.

At the same time, it is important to note that despite being highly religious, individuals who lacked quality social connections had overall lower levels of purpose in life than individuals who had strong social connections, reinforcing the central importance of social relationships feeding into purpose in life. Thus, we certainly do not suggest that individuals who lack social disconnection rely on or adopt religious beliefs. Although for the highly religious, these beliefs may act as a buffer to loss of purpose in life, it is also possible that relying on these beliefs may discourage individuals from reconnecting with others over time, unnecessarily prolonging social disconnection.

\section{7 | LIMITATIONS AND FUTURE DIRECTIONS}

We recognize that given the correlational nature of our findings, it also remains an open interpretation that being socially connected is what buffers the relationship between religiosity and purpose in life. Additionally, although we use large data sets that adequately power our analyses of interest, we recognize that when a model with covariates is used, cases are eliminated due to incomplete data on various different measures, which may bias analyses. However, using a fullinformation maximum likelihood model and using a model without covariates does not significantly alter the pattern of results. Further, how we operationalize our constructs of social connection and religiosity is limited by the variables available in these extant data sets. However, our convergent results with three large, representative data sets (i.e., the HRS, MIDUS 2, and MIDUS 3; also see supplemental material), including different operationalization of our psychosocial measures of interest, bolster our confidence in our model and in these findings.

Although we propose two primary reasons why religion may compensate for purpose-providing a broader worldview and providing social substitution-we acknowledge that our present data cannot separate the unique contribution of each reason in substituting for purpose in life. Additionally, 
other mechanisms for how religion could buffer loss of purpose in life from social disconnection remain unexamined. For example, it is possible that religion simply distracts individuals from thinking about their negative experiences rather than providing a reassuring worldview or serving as a social substitute.

Lastly, we note that the data we examined are from the predominantly Christian United States. It remains unclear how these patterns may differ in countries that are predominantly of other religions; for example, social substitution may function differently in polytheistic religions. Similarly, it remains unclear whether belief systems that are nonreligious, like holding a scientific worldview, can provide the same benefits for individuals who lack social connection, and whether simply being prompted to think about the world as planned and purposeful, regardless of an enduring belief in these propositions, can also act to counter these social threats to purpose.

\section{CONCLUSION}

Lacking social connection or being rejected threatens individuals' perceptions of purpose in life. However, under this threat, individuals who have strong religious beliefs to turn to may be able to partly compensate for this purpose that social connection would otherwise provide.

\section{ACKNOWLEDGMENT}

The authors thank Koji Takahashi for his comments on the analyses for Study 3. Preparation of this manuscript was supported by a doctoral fellowship awarded to Todd Chan by the Social Sciences and Humanities Research Council of Canada.

\section{CONFLICT OF INTERESTS}

The author(s) declared no potential conflicts of interest with respect to the research, authorship, and/or publication of this article.

\section{ENDNOTES}

${ }^{1}$ We also examined the present hypothesis in the MIDUS 1 using nearly parallel measures. We find the same pattern of results (see the online supplementary material).

${ }^{2}$ Of note, although we use some measures in Study 1 and Study 2 that are conceptually similar, they are distinct data collections. As such, the items used to assess loneliness and religiosity in Study 1 were not available for analysis in Study 2.

${ }^{3}$ In Study 1, this scale was measured on a 6-point scale.
${ }^{4}$ The model with covariates has weaker interactive effects, but the model holds. In this case, the strength of the relationship between religiosity at Time 1 and purpose in life at Time 2 varies less so depending on friendship quality (estimate $=-0.12, S E=0.06, z=$ $1.89, p=.059$ ). Nonetheless, the primary relationship holds: For individuals with low friendship quality, religiosity positively predicts purpose in life (estimate $=0.137, S E=0.045, z=3.01, p=.003$ ), but religiosity does not predict purpose in life for individuals with high friendship quality.

\section{REFERENCES}

Aydin, N., Fischer, P., \& Frey, D. (2010). Turning to God in the face of ostracism: Effects of social exclusion on religiousness. Personality and Social Psychology Bulletin, 36, 742-753. https:// doi.org/10.1177/0146167210367491

Baumeister, R. F. (1991). Meanings of life. New York, NY: Guilford Press.

Baumeister, R. F., \& Leary, M. R. (1995). The need to belong: Desire for interpersonal attachments as a fundamental human motivation. Psychological Bulletin, 117, 497-529. https://doi. org/10.1037/0033-2909.117.3.497

Berger, P. L. (1967). The sacred canopy: Elements of a sociological theory of religion. New York, NY: Open Road Media.

Bondevik, M., \& Skogstad, A. (2000). Loneliness, religiousness, and purpose in life in the oldest old. Journal of Religious Gerontology, 11, 5-21. https://doi.org/10.1300/J078v11n01_03

Brown, S. L., Nesse, R. M., House, J. S., \& Utz, R. L. (2004). Religion and emotional compensation: Results from a prospective study of widowhood. Personality and Social Psychology Bulletin, 30, 1165-1174. https://doi.org/10.1177/0146167204263752

Burke, B. L., Martens, A., \& Faucher, E. H. (2010). Two decades of terror management theory: A meta-analysis of mortality salience research. Personality and Social Psychology Review, 14, 155-195. https://doi.org/10.1177/1088868309352321

Cacioppo, J. T., Hawkley, L. C., \& Berntson, G. G. (2003). The anatomy of loneliness. Current Directions in Psychological Science, 12, 71-74. https://doi.org/10.1111/1467-8721.01232

Chamberlain, K., \& Zika, S. (1992). Religiosity, meaning in life, and psychological well-being. Religion and Mental Health, 138-148.

Crocker, J., Luhtanen, R. K., Cooper, M. L., \& Bouvrette, A. (2003). Contingencies of self-worth in college students: Theory and measurement. Journal of Personality and Social Psychology, 85, 894-908. https://doi.org/10.1037/0022-3514.85.5.894

Dunbar, R. I. M. (2018). The anatomy of friendship. Trends in Cognitive Sciences, 22, 32-51. https://doi.org/10.1016/j.tics.2017.10.004

Ebersole, P. (1998). Types and depth of written life meanings. In P. T. P. Wong, \& P. S. Fry (Eds.), The human quest for meaning: A handbook of psychological research and clinical applications (pp. 179-191). Mahwah, NJ: Erlbaum.

Epley, N., Akalis, S., Waytz, A., \& Cacioppo, J. T. (2008). Creating social connection through inferential reproduction: Loneliness and perceived agency in gadgets, gods, and greyhounds. Psychological Science, 19, 114-120. https://doi. org/10.1111/j.1467-9280.2008.02056.x

Epley, N., Waytz, A., Akalis, S., \& Cacioppo, J. T. (2008). When we need a human: Motivational determinants of anthropomorphism. 
Social Cognition, 26, 143-155. https://doi.org/10.1521/ soco.2008.26.2.143

Epley, N., Waytz, A., \& Cacioppo, J. T. (2007). On seeing human: A three-factor theory of anthropomorphism. Psychological Review, 114, 864-886. https://doi.org/10.1037/0033-295X.114.4.864

Farias, M., Newheiser, A.-K., Kahane, G., \& De Toledo, Z. (2013). Scientific faith: Belief in science increases in the face of stress and existential anxiety. Journal of Experimental Social Psychology, 49, 1210-1213. https://doi.org/10.1016/j.jesp.2013.05.008

Fetzer Institute. (2003). Multidimensional measurement of religiousness/spirituality for use in health research: A report of the Fetzer Institute/National Institute on Aging Working Group. Kalamazoo, MI: John E. Fetzer Institute.

Frazier, P. (2005). Meaning in life: One link in the chain from religiousness to well-being. Journal of Counseling Psychology, 52, 574582. https://doi.org/10.1037/0022-0167.52.4.574

Gebauer, J. E., \& Maio, G. R. (2012). The need to belong can motivate belief in God. Journal of Personality, 80, 465-501. https://doi. org/10.1111/j.1467-6494.2011.00730.x

George, L. S., \& Park, C. L. (2013). Are meaning and purpose distinct? An examination of correlates and predictors. Journal of Positive Psychology, 8, 365-375. https://doi.org/10.1080/17439760.2013 .805801

Gignac, G. E., \& Szodorai, E. T. (2016). Effect size guidelines for individual differences researchers. Personality and Individual Differences, 102, 74-78. https://doi.org/10.1016/j. paid.2016.06.069

Granqvist, P., \& Hagekull, B. (2000). Religiosity, adult attachment, and why "singles" are more religious. International Journal for the Psychology of Religion, 10, 111-123. https://doi.org/10.1207/ S15327582IJPR1002_04

Granqvist, P., Mikulincer, M., \& Shaver, P. R. (2009). Religion as attachment: Normative processes and individual differences. Personality and Social Psychology Review, 14, 49-59.

Haslam, S. A., Jetten, J., Postmes, T., \& Haslam, C. (2009). Social identity, health and well-being: An emerging agenda for applied psychology. Applied Psychology, 58, 1-23. https://doi. org/10.1111/j.1464-0597.2008.00379.x

Hawkley, L. C., \& Cacioppo, J. T. (2010). Loneliness matters: A theoretical and empirical review of consequences and mechanisms. Annals of Behavioral Medicine, 40, 218-227. https://doi. org/10.1007/s12160-010-9210-8

Heinrich, L. M., \& Gullone, E. (2006). The clinical significance of loneliness: A literature review. Clinical Psychology Review, 26, 695-718. https://doi.org/10.1016/j.cpr.2006.04.002

Hicks, J. A., \& King, L. A. (2008). Religious commitment and positive mood as information about meaning in life. Journal of Research in Personality, 42, 43-57. https://doi.org/10.1016/j.jrp.2007.04.003

Hicks, J. A., \& King, L. A. (2009). Positive mood and social relatedness as information about meaning in life. Journal of Positive Psychology, 4, 471-482. https://doi.org/10.1080/17439760903271108

Hicks, J. A., Schlegel, R. J., \& King, L. A. (2010). Social threats, happiness, and the dynamics of meaning in life judgments. Personality and Social Psychology Bulletin, 36, 1305-1317. https://doi. org/10.1177/0146167210381650

Hill, P. L., \& Turiano, N. A. (2014). Purpose in life as a predictor of mortality across adulthood. Psychological Science, 25, 14821486. https://doi.org/10.1177/0956797614531799
Holt-Lunstad, J., Smith, T. B., \& Layton, J. B. (2010). Social relationships and mortality risk: a meta-analytic review. PLoS Medicine, 7, e1000316.

House, J. S., Landis, K. R., \& Umberson, D. (1988). Social relationships and health. Science, 241, 540-545. https://doi.org/10.1126/ science.3399889

Kawachi, I., \& Berkman, L. F. (2001). Social ties and mental health. Journal of Urban Health, 78, 458-467. https://doi.org/10.1093/ jurban/78.3.458

Kay, A. C., Gaucher, D., McGregor, I., \& Nash, K. (2009). Religious belief as compensatory control. Personality and Social Psychology Review, 14, 37-48.

Kay, A. C., Gaucher, D., Napier, J. L., Callan, M. J., \& Laurin, K. (2008). God and the government: Testing a compensatory control mechanism for the support of external systems. Journal of Personality and Social Psychology, 95, 18-35. https://doi. org/10.1037/0022-3514.95.1.18

Kay, A. C., Whitson, J. A., Gaucher, D., \& Galinsky, A. D. (2009). Compensatory control. Current Directions in Psychological Science, 18, 264-268. https://doi. org/10.1111/j.1467-8721.2009.01649.x

Kirkpatrick, L. A., Shillito, D. J., \& Kellas, S. L. (1999). Loneliness, social support, and perceived relationships with God. Journal of Social and Personal Relationships, 16, 513-522. https://doi. org/10.1177/0265407599164006

Klinger, E. (1998). The search for meaning in evolutionary perspective and its clinical implications. In P. T. P. Wong, \& P. S. Fry (Eds.), The human quest for meaning: A handbook of psychological research and clinical applications (pp. 27-50). Mahwah, NJ: Erlbaum.

Krause, N. (2003). Religious meaning and subjective well-being in late life. Journals of Gerontology, Series B: Psychological Sciences and Social Sciences, 58, S160-S170.

Krause, N. (2004). Stressors arising in highly valued roles, meaning in life, and the physical health status of older adults. Journals of Gerontology, Series B: Psychological Sciences and Social Sciences, 59, S287-S297.

Krause, N. (2007a). Evaluating the stress-buffering function of meaning in life among older people. Journal of Aging and Health, 19, 792-812.

Krause, N. (2007b). Longitudinal study of social support and meaning in life. Psychology and Aging, 22, 456-469.

Krause, N. (2009). Meaning in life and mortality. Journals of Gerontology, Series B: Psychological Sciences and Social Sciences, 64B, 517-527. https://doi.org/10.1093/geronb/gbp047

Lambert, N. M., Stillman, T. F., Hicks, J. A., Kamble, S., Baumeister, R. F., \& Fincham, F. D. (2013). To belong is to matter: Sense of belonging enhances meaning in life. Personality and Social Psychology Bulletin, 39, 1418-1427. https://doi. org/10.1177/0146167213499186

Laurin, K., Schumann, K., \& Holmes, J. G. (2014). A relationship with God? Connecting with the divine to assuage fears of interpersonal rejection. Social Psychological and Personality Science, 5, 777785. https://doi.org/10.1177/1948550614531800

Martela, F., \& Steger, M. F. (2016). The three meanings of meaning in life: Distinguishing coherence, purpose, and significance. Journal of Positive Psychology, 1-15. https://doi.org/10.1080/1 7439760.2015 .1137623 
McIntosh, D. N. (1995). Religion-as-schema, with implications for the relation between religion and coping. International Journal for the Psychology of Religion, 5, 1-16. https://doi.org/10.1207/ s15327582ijpr0501_1

McKnight, P. E., \& Kashdan, T. B. (2009). Purpose in life as a system that creates and sustains health and well-being: An integrative, testable theory. Review of General Psychology, 13, 242-251. https://doi.org/10.1037/a0017152

Niemyjska, A., \& Drat-Ruszczak, K. (2013). When there is nobody, angels begin to fly: Supernatural imagery elicited by a loss of social connection. Social Cognition, 31, 57-71. https://doi.org/10.1521/ soco.2013.31.1.57

Park, C. L. (2005). Religion as a meaning-making framework in coping with life stress. Journal of Social Issues, 61, 707-729. https://doi. org/10.1111/j.1540-4560.2005.00428.x

Park, C. L., \& Cohen, L. H. (1993). Religious and nonreligious coping with the death of a friend. Cognitive Therapy and Research, 17, 561-577. https://doi.org/10.1007/BF01176079

Pinquart, M. (2002). Creating and maintaining purpose in life in old age: A meta-analysis. Ageing International, 27, 90-114. https:// doi.org/10.1007/s12126-002-1004-2

Pollner, M. (1989). Divine relations, social relations, and well-being. Journal of Health and Social Behavior, 30, 92-104. https://doi. org/10.2307/2136915

Prentice, D. A., \& Miller, D. T. (1992). When small effects are impressive. Psychological Bulletin, 112, 160-164. https://doi. org/10.1037/0033-2909.112.1.160

Reker, G. T., Peacock, E. J., \& Wong, P. T. (1987). Meaning and purpose in life and well-being: A life-span perspective. Journal of Gerontology, 42, 44-49. https://doi.org/10.1093/geronj/42.1.44

Ren, D., Wesselmann, E., \& Williams, K. D. (2016). Evidence for another response to ostracism: Solitude seeking. Social Psychological and Personality Science, 7, 204-212. https://doi. org/10.1177/1948550615616169

Russell, D. W. (1996). UCLA Loneliness Scale (Version 3): Reliability, validity, and factor structure. Journal of Personality Assessment, 66, 20-40. https://doi.org/10.1207/s15327752jpa6601_2

Ryff, C. D., \& Keyes, C. L. M. (1995). The structure of psychological well-being revisited. Journal of Personality and Social Psychology, 69, 719-727. https://doi.org/10.1037/0022-3514.69.4.719

Ryff, C. D., \& Singer, B. (1998). The contours of positive human health. Psychological Inquiry, 9, 1-28. https://doi.org/10.1207/ s15327965pli0901_1
Ryff, C. D., Singer, B. H., \& Palmersheim, K. A. (2004). Social inequalities in health and well-being: The role of relational and religious protective factors. In O. G. Brim, C. D. Ryff, \& R. C. Kessler (Eds.), How healthy are we? A national study of well-being at midlife (pp. 90-123). Chicago, IL: University of Chicago Press.

Stavrova, O., Ehlebracht, D., \& Fetchenhauer, D. (2016). Belief in scientific-technological progress and life satisfaction: The role of personal control. Personality and Individual Differences, 96, 227-236. https://doi.org/10.1016/j.paid.2016.03.013

Steger, M. F., Oishi, S., \& Kashdan, T. B. (2009). Meaning in life across the life span: Levels and correlates of meaning in life from emerging adulthood to older adulthood. Journal of Positive Psychology, 4, 43-52. https://doi.org/10.1080/17439760802303127

Stillman, T. F., Baumeister, R. F., Lambert, N. M., Crescioni, A. W., DeWall, C. N., \& Fincham, F. D. (2009). Alone and without purpose: Life loses meaning following social exclusion. Journal of Experimental Social Psychology, 45, 686-694. https://doi. org/10.1016/j.jesp.2009.03.007

Walen, H. R., \& Lachman, M. E. (2000). Social support and strain from partner, family, and friends: Costs and benefits for men and women in adulthood. Journal of Social and Personal Relationships, 17, 5-30. https://doi.org/10.1177/0265407500171001

Wong, P. T. P. (1998). Implicit theories of meaningful life and the development of the Personal Meaning Profile. In P. T. P. Wong, \& P. S. Fry (Eds.), The human quest for meaning: A handbook of psychological research and clinical applications (pp. 111-140). Mahwah, NJ: Erlbaum.

Zika, S., \& Chamberlain, K. (1992). On the relation between meaning in life and psychological well-being. British Journal of Psychology, 83, 133-145. https://doi.org/10.1111/j.2044-8295.1992.tb02429.x

\section{SUPPORTING INFORMATION}

Additional Supporting Information may be found online in the supporting information tab for this article.

How to cite this article: Chan T, Michalak NM, Ybarra O. When God is your only friend: Religious beliefs compensate for purpose in life in the socially disconnected. J Pers. 2019;87:455-471. https://doi. org/10.1111/jopy.12401 